\title{
Bone Metastasis in Thyroid Cancer: A Literature Review
}

Seda Sezen Göktaş*

Department of Head and Neck Surgery, Bezmialem Vakif University, Turkey

*Corresponding author: Seda Sezen Göktaş, Department of Head and Neck Surgery, Bezmialem Vakif University, Turkey, Tel: +09 $546 \quad 438 \quad 24$ 11; Email: sedasezengoktas@gmail.com

\section{Introduction}

Thyroid cancer is the most common endocrine cancer [1]. It is the third most common newly diagnosed cancer in the population aged 20-39 years. The number of cases diagnosed annually is about 4 times that of males in females (5-7 in females and 1-4 in males in 100,000 cases) [2].

About $90 \%$ of thyroid cancers are differentiated thyroid cancers. Approximately $85 \%$ of follicular cell derived tumors constitute papillary carcinoma and $12 \%$ of it constitute follicular carcinoma including conventional and oncocytic (Hurtle cell) carcinomas [3]. Differentiated thyroid cancers develop from thyroid follicular cells. The survival rates of differentiated thyroid cancers are quite high. The 10-year survival rate is reported as $93 \%$ for papillary carcinoma and $85 \%$ for follicular carcinoma [4]. However, 10-year survival rate of distant metastatic papillary thyroid cancer is reported as $70 \%$ [5]. A small group (approximately <3\%) of undifferentiated-anaplastic tumors arising from follicular cells, an aggressive tumor with invasive and early metastases, survival expectancy in anaplastic carcinomas is 3-6 months [6-8]. $20-30 \%$ of anaplastic cancers have syncrhonous differentiated thyroid cancer with papillary cancer in the majority [9]. Anaplastic thyroid cancer is clinically considered as stage 4 [10]. Medullary thyroid carcinoma originating from parafollicular cells constitutes approximately $1-2 \%$ of total thyroid carcinomas. It may be sporadic (about 75\%) or hereditary. Hereditary form is associated with multiple endocrine neoplasia type $2 \mathrm{~A}$ and B (MEN-2A, MEN-2B) and familial medullary thyroid carcinoma. Life expectancy in medullary carcinoma is about 8.6 years [11].

The rate of distant metastasis in differentiated cancers has been reported at $4-23 \%$ in various studies [12-16].
The most common site of distant metastasis is the upper mediastinal lymph nodes and lung $(\% 61,5)[17,18]$. These are followed by bone $(21.2 \%)$, hilar lymph nodes, liver and brain [19]. In addition, skin, adrenal gland, kidney, bronchial submucosa, digestive system, and omentum metastasis has been reported [20-24]. Synchronous metastases in the lung and bone have been reported in $15 \%$ of cases [25]. The most important prognostic factors for metastatic disease are complete control of local disease and radioactive iodine sensitivity [26]. According to general acceptance in the literature; bone metastasis and distant metastasis resistant to radioactive iodine therapy are independent poor prognostic factors $[13,27$ 29].

Among tumors that metastasize to the bone, thyroid cancers are the third most common [30]. Bone metastasis rate in differentiated thyroid carcinomas has been reported between $2 \%$ and $13 \%$. Bone metastasis is especially common in advanced stages of follicular carcinoma [31]. Bone metastasis in follicular cancer is between $7 \%$ and $28 \%$, whereas in papillary thyroid cancer this rate is $1.4-7 \%[32,33]$. However, since the number of papillary thyroid cancer patients is higher, some authors argue that the number of papillary thyroid cancer patients will be higher in terms of bone metastasis, and therefore these patients must be carefully screened [34]. Approximately $12 \%$ of Hurthle cell carcinomas show vertebral metastases [25].

About 600,000 patients per year are diagnosed with bone metastasis in the USA [35]. Bone is the third most common metastatic site after lung and liver. Bone metastatic disease is more frequent in patients over 40 years of age [36]. Bone metastatic disease consists of five steps: (1) separation from the primary tumor; (2) entry into the lymphatic and / or blood vessels; (3) surviving 


\section{Otolaryngology Open Access Journal}

and travelling in circulation; (4) reaching the target bone tissue; and (5) living in the new bone environment [37].

Bone metastasis is associated with excess blood flow. However, malignant cells synthesize adhesive molecules that allow for attachment to the bone matrix. It also synthesizes substances that promote angiogenesis and substances that increase bone resorption by activating osteoclasts (IL-1, IL-6, and RANKL) and provide the appropriate environment to replicate in this bone [34]. Metastatic lesions usually cause osteolysis [33].

Bone metastases are frequently seen in the vertebral, pelvis, femur, skull, femur and costa bones [38]. The rate of metastasis to facial bones was $2 \%$, the most frequent was follicular thyroid cancer, and the most frequent metastatic site was reported as mandibula [39-41]. Vertebral metastases are $60-80 \%$ thoracic, $15-30 \%$ lumbar and $<10 \%$ cervical 25 . And infiltrates the corpus of the vertebrate, and often the posterior part [42]. The lesion is often asymptomatic, but it becomes symptomatic when infiltrate the surrounding tissues or pressure the neural structures. The most common symptom is pain, and the other symptoms are fractures, spinal cord edema, and spinal instability $[31,33]$. Bone metastasis is also the most common cause of cancer-related pain [30].

In various studies, 10-year survival of bone metastatic thyroid cancer cases was reported between 0-34\% [16,43-45]. In a study with 444 patients, 20 years of survival in patients with RAI uptake was $33 \%$, while 10 years survival was $3 \%$ without RAI uptake [27].

The first option is direct radiography for diagnosis, but may not be visible lesions less than $1 \mathrm{~cm}$. In one study, 8 of 115 patients with bone metastasis had no pathology detected by X-ray [27]. Computed tomography (CT) is valuable in assessing lesion spread. Diagnostic sensivity of CT have been reported between $71 \%$ and $100 \%$ [33]. Magnetic resonance imaging (MRI) allows evaluation of both bone and bone marrow. MRI is particularly useful in distinguishing compression and tumor infiltration in the spinal cord. In a study of several different types of cancers that metastasize bone, the sensivities of whole body MRI scans were $94 \%$ and the diagnostic accuracy was $91 \%$ [46].

Bone scintigraphy is often a successful test to distinguish the osteoblastic reaction. Because of bone metastasis of thyroid carcinoma is frequently present with lytic lesions, the false positivity and false negativity rates of the bone scintigraphy is high [47]. 2-Deoxy-2-
(18F) fluoro-D-glucose Positron Emission Tomography (FDG-PET) is a useful assay in poorly differentiated metastatic tumors. Especially the FDG-PET with recombinant human TSH (rhTSH) stimulation has been found useful to determine the bone metastases [48]. FDGPET, Technetium 99 sestamibi (MIBI) and I-131 whole body scanning scintigraphy were compared to determine the location of bone metastasis in 19 patients, and there was no significant difference between these techniques [49]. However, FDG-PET positivity has been associated with very poorly prognosis [50]. A promising method for bone metastasis is I-124-PET-CT, which works by way of sodium iodide uptake and presents a 3-dimensional tumor image. In a study with thyroid cancer cases, the diagnostic values of I-131, I-124, CT and I-124-PET-CT were compared and the diagnostic accuracy rates were $83 \%, 87 \%, 56 \%$ and $100 \%$, respectively [51]. Consequently, the most accurate approach to bone metastasis is the detailed examination of the region with metastatic focus by MRI or CT if metastatic tumor is detected with one of the whole body screening methods. If spinal cord invasion is suspected, then the whole body MRI will be useful.

Biopsy is not recommended for lesions with I-131 uptake in bone metastatic thyroid cancer. In addition, biopsy from the bone lesion is not required for recurrent disease with previously documented bone metastasis [34]. However, if bone metastasis is the initial focus of recurrent disease, bone biopsy is recommended [52]. In the evaluation of a newly developed bone lesion in a patient with extensive bone metastasis, it is decided according to the clinical indication whether a biopsy is necessary [34].

Treatment options for bone metastatic thyroid cancer include RAI, surgical resection, external radiotherapy, arterial embolization, systemic bisphosphonates or chemotherapy and percutaneous imaging-guided therapies [34,53]. Surgical treatment is considered the first choice in bone metastasis [32]. Complete surgical resection means pathologically clean surgical margins. Palliative surgical resection means that the tumor has been minimized, or the tumor has been found in other organs when the bone tumor has been completely cleared [34]. Surgical indications for bone metastasis can be listed as follows; persistent pain to unresponsive to medical treatment, low radioactive iodine uptake, neural compression or spinal cord involvement [33]. According to the literature, metastasectomy in patients with bone metastasis of 5 or less increases the quality of life and survival time $[33,44]$. In vertebral metastases, in addition 


\section{Otolaryngology Open Access Journal}

to surgical approach, RAI and TSH suppression and palliative methods such as laminectomy, embolization and external radiotherapy are recommended [31,54,55]. In cases of cord compression due to follicular carcinoma of the cervical vertebra metastasis, resection of metastatic lesion with total thyroidectomy and additionally RAI, external radiotherapy and TSH suppression are recommended $[31,56]$. Glucocorticoid treatment is added in the presence of cord pressure [57]. Percutaneous vertebroplasty and kyphoplasty are used as alternative surgical methods to surgical resection in patients with pathologic fractures. In these methods, bone cement inject to the vertebral body, which is bent or broken due to metastasis. Studies have shown that pain and deformity can be reduced in this way $[51,58]$.

As the metastatic tumor increases osteoclastic activity, the use of bisphosphonates that inhibit osteoclasts has been recommended. Studies on IV pamidoranate treatment have provided effective symptomatic treatment with low side effect $[59,60]$. In a study comparing zoledronic acid and pamidronate treatments, the treatment efficacy was higher in the zoledronic acid group and the rate of complication with skeletal metastasis was significantly lower [61].

Studies have shown that bone metastasis is generally resistant to RAI therapy $[16,33,62,63]$. The response rate to RAI treatment is approximately 55\% [64]. It has been suggested that external radiotherapy can be used following surgical treatment in bone metastasis with RAI therapy resistant $[32,65]$. However, this treatment provides palliative healing in symptomatic metastases, especially effective for pain [66].

External beam radiation therapy (EBRT) is performed for preserving the functional capacity, especially after surgical treatment of pathologic fractures or in patients with high risk of fractures. Side effects are erythema, skin dryness, mucositis, late hyperpigmentation of the skin and esophageal and tracheal stenosis [34]. In intensity modulated radiation therapy (IMRT), radiation can be delivered more precisely to sites outside the thyroid bed, provides better preservation of the surrounding healthy tissue, and reduced early and late radiation toxicity [67]. This method was observed to have significantly less late radiation-related morbidity compared with EBRT (2\% and 22\%) [68]. Radiofrequency ablation is also a minimally invasive technique that leads to coagulation necrosis in the targeted tumoral tissue. It has been shown to reduce pain $[69,70]$. Another treatment method is cryotherapy. In the literature, there is a study of 14 cases treated with cryotherapy without any neurovascular damage or pathologic fractures [71]. Selective embolization of the artery of the tumor was performed in a study, and pain and neurological symptoms are relieved immediately in $59 \%$ of patients [72].

SRC (protooncogene SRC) is an oncogene. It is highly expressed in osteoclasts that encode a tyrosine kinase that promotes cellular proliferation and has a crucial importance in the osteoclast cytoskeleton $[73,74]$. The effects of the SRC inhibitors dasatinib and saracatinib in the treatment of bone metastatic disease are being investigated in various studies $[75,76]$.

Elevated TGF-b production in metastatic bone results in increased tumor cell invasiveness, angiogenesis and immunosuppression at the same time. Thus blocking the TGF-b signaling pathway is also a promising method for the treatment of bone metastatic disease. For this purpose, TGF-b neutralizing antibodies (1D11, Fresolimumab), tyrosine kinase inhibitors (LY2109761, LY2157299), and soluble receptor proteins have been developed and tested in various preclinical studies $[77,78]$. Denosumab is completely human monoclonal to RANKL and inhibits osteoclast activity [79]. It have been considered to be more effective than zoledronic acid in the prevention or delay of skeletal morbidities in bone metastases of solid tumors [80].

Another treatment option is a micro-RNAs. In an animal study by Ell, et al. [81] it was demonstrated that miR-141 and miR-219 can prevent osteoclast differentiation and bone metastasis. It has been suggested that miR-16 and miR-378 may also be valuable biomarkers for bone metastasis. These findings highlight miRNAs as exciting new strategies for the diagnosis and treatment of cancer skeletal metastasis [81]. Similarly, miR-34a has been found to be effective in inhibiting osteoclast differentiation, bone resorption and skeletal metastasis. A study have shown that in miR-34a overexpressed mice, osteoclast production and bone resorption are decreased and the mice are resistant to bone metastasis of breast cancer and melanoma [82].

In conclusion, early diagnosis and treatment of bone metastasis of thyroid carcinoma can reduced mortality rates. Pain can be a warning symptom of bone metastasis in risky patients. I-131, I-124, FDG-PET CT and I-124-PET CT can be used for whole body scanning in suspected patients and CT, MRI, or X-ray are useful after detection tumor location. Treatment options include curative or palliative surgery or minimally invasive techniques (such 


\section{Otolaryngology Open Access Journal}

as radiofrequency ablation, cryotherapy, selective arterial embolization) or RAI, EBRT, IMRT, or medication (such as bisphosphonates and human monoclonal antibody).

\section{References}

1. DeLellis RA, Lloyd RV, Heitz PU (2004) WHO paraganglioma. In: IARC WHO Classification of Tumours. Lyon: IARC Press.

2. Fidler MM, Gupta S, Soerjomataram I, Ferlay J, Steliarova-Foucher E, et al. (2017) Cancer incidence and mortality among young adults aged 20-39 years worldwide in 2012: a population-based study. Lancet Oncol 18(12):1579-1589.

3. Aschebrook-Kilfoy B, Ward MH, Sabra MM, Devesa SS (2011) Thyroid cancer incidence patterns in the United States by histologic type, 1992-2006. Thyroid 21(2): 125-134.

4. Hundahl SA, Fleming ID, Fremgen AM, Menck HR (1998) A National Cancer Data Base report on 53,856 cases of thyroid carcinoma treated in the U.S., 19851995. Cancer 83(12): 2638-2648.

5. Lin J-D, Hsueh C, Chao T-C (2015) Long-Term FollowUp of the Therapeutic Outcomes for Papillary Thyroid Carcinoma With Distant Metastasis. Medicine (Baltimore) 94(26): e1063.

6. Zivaljevic V, Tausanovic K, Paunovic I (2014) Age as a prognostic factor in anaplastic thyroid cancer. Int J Endocrinol 2014: 240513.

7. Kwon J, Kim BH, Jung H-W, Besic N, Sugitani I, et al. (2016) The prognostic impacts of postoperative radiotherapy in the patients with resected anaplastic thyroid carcinoma: A systematic review and metaanalysis. Eur J Cancer 59: 34-45.

8. Smallridge RC, Copland JA (2010) Anaplastic thyroid carcinoma: pathogenesis and emerging therapies. Clin Oncol (R Coll Radiol) 22(6): 486-497.

9. McIver B, Hay ID, Giuffrida DF, Dvorak CE, Grant CS, et al. (2001) Anaplastic thyroid carcinoma: a 50-year experience at a single institution. Surgery 130(6): 1028-1034.

10. Smallridge RC, Ain KB, Asa SL, Bible KC, Brierley JD, et al. (2012) American Thyroid Association Guidelines for Management of Patients with Anaplastic Thyroid Cancer. Thyroid 22(11): 1104-1139.
11. Konstantinidis A, Stang M, Roman SA, Sosa JA (2017) Surgical management of medullary thyroid carcinoma. Updates Surg 69(2): 151-160.

12. Jonklaas J, Sarlis NJ, Litofsky D, Ain KB, Bigos ST, et al. (2006) Outcomes of patients with differentiated thyroid carcinoma following initial therapy. Thyroid 16(12): 1229-1242.

13. Sampson E, Brierley JD, Le LW, Rotstein L, Tsang RW (2007) Clinical management and outcome of papillary and follicular (differentiated) thyroid cancer presenting with distant metastasis at diagnosis. Cancer 110(7): 1451-1456.

14. Nixon IJ, Whitcher MM, Palmer FL, Tuttle RM, Shaha AR, et al. (2012) The Impact of Distant Metastases at Presentation on Prognosis in Patients with Differentiated Carcinoma of the Thyroid Gland. Thyroid 22(9): 884-889.

15. Sugitani I, Fujimoto Y, Yamamoto N (2008) Papillary thyroid carcinoma with distant metastases: survival predictors and the importance of local control. Surgery 143(1): 35-42.

16. Schlumberger M, Vathaire F De, Travagli J, Travagli JP, Gardet P, et al. (1996) Radioactive iodine treatment and external radiotherapy for lung and bone metastases from thyroid carcinoma. J Nucl Med 37(4): 598-605.

17. Song HJ, Qiu ZL, Shen CT, Wei WJ, Luo QY (2015) Pulmonary metastases in differentiated thyroid cancer: efficacy of radioiodine therapy and prognostic factors. Eur J Endocrinol 173(3): 399-408.

18. Pomorski L, Bartos M (1999) Metastasis as the first sign of thyroid cancer. Neoplasma 46(5): 309-312.

19. Haq M, Harmer C (2005) Differentiated thyroid carcinoma with distant metastases at presentation: prognostic factors and outcome. Clin Endocrinol (Oxf) 63(1): 87-93.

20. Niederle B, Roka R, Schemper M, Fritsch A, Weissel M, et al. (1986) Surgical treatment of distant metastases in differentiated thyroid cancer: indication and results. Surgery 100(6): 1088-1097.

21. Koller EA, Tourtelot JB, Pak HS, Cobb MW, Moad JC, et al. (1998) Papillary and Follicular Thyroid Carcinoma Metastatic to the Skin: A Case Report and Review of the Literature. Thyroid 8(11): 1045-1050. 


\section{Otolaryngology Open Access Journal}

22. Orsolon P, Bagni B, Geatti O, Guerra UP (1996) An unusual adrenal metastasis secondary to Hürthle cell carcinoma of the thyroid. Clin Nucl Med 21(4): 312 315.

23. Smallridge RC, Castro MR, Morris JC, Young PR, Reynolds JC, et al. (2001) Renal metastases from thyroid papillary carcinoma: study of sodium iodide symporter expression. Thyroid 11(8): 795-804.

24. Nomori H, Horio H, Mimura T, Morinaga S (1997) Massive Hemoptysis from an Endobronchial Metastasis of Thyroid Papillary Carcinoma. Thorac Cardiovasc Surg 45(4): 205-207.

25. Ramadan S, Ugas MA, Berwick RJ, Manisha Notay, Hyongyu Cho, et al. (2012) Spinal metastasis in thyroid cancer. Head Neck Oncol 4: 39.

26. Lee J, Soh EY (2010) Differentiated Thyroid Carcinoma Presenting with Distant Metastasis at Initial Diagnosis clinical outcomes and prognostic factors. Ann Surg 251(1): 114-119.

27. Durante C, Haddy N, Baudin E, Leboulleux S, Hartl D, et al. (2006) Long-Term Outcome of 444 Patients with Distant Metastases from Papillary and Follicular Thyroid Carcinoma: Benefits and Limits of Radioiodine Therapy. J Clin Endocrinol Metab 91(8): 2892-2899.

28. Lin JD, Huang MJ, Juang JH, Chao TC, Huang BY, et al. (1999) Factors Related to the Survival of Papillary and Follicular Thyroid Carcinoma Patients with Distant Metastases. Thyroid 9(12): 1227-1235.

29. Lang BHH, Wong KP, Cheung CY, Wan KY, Lo CY (2013) Evaluating the prognostic factors associated with cancer-specific survival of differentiated thyroid carcinoma presenting with distant metastasis. Ann Surg Oncol 20(4): 1329-1335.

30. Coleman RE (2006) Clinical Features of Metastatic Bone Disease and Risk of Skeletal Morbidity. Clin Cancer Res 12(20): 6243-6249.

31. Hsiao FC, Chen CL, Lin TY, Yi-Jen Hung, Ming-Fang Cheng, et al. (2008) Metastatic Spinal Cord Compression as Initial Presentation of Occult Follicular Thyroid Carcinoma. J Med Sci 28(2): 89-93.

32. Leger AF (1995) Distant metastasis of differentiated thyroid cancers. Diagnosis by 131 iodine (I 131) and treatment]. Ann Endocrinol 56(3): 205-208.
33. Muresan MM, Olivier $P$, Leclère J, Sirveaux F, Brunaud L, et al. (2008) Bone metastases from differentiated thyroid carcinoma. Endocr Relat Cancer 15(1): 37-49.

34. Wexler JA (2011) Approach to the thyroid cancer patient with bone metastases. J Clin Endocrinol Metab 96(8): 2296-2307.

35. Randall RL (2014) A Promise to Our Patients with Metastatic Bone Disease. Ann Surg Oncol 21(13): 4049-4050.

36. Davila D, Antoniou A, Chaudhry MA (2015) Evaluation of Osseous Metastasis in Bone Scintigraphy. Semin Nucl Med 45(1): 3-15.

37. Krzeszinski JY, Wan Y (2015) New therapeutic targets for cancer bone metastasis. Trends Pharmacol Sci 36(6): 360-373.

38. Varadarajan VV, Pace EK, Patel V, Sawhney R, Amdur RJ, et al. (2017) Follicular thyroid carcinoma metastasis to the facial skeleton: A systematic review. BMC Cancer 17(1): 1-8.

39. Friedrich RE, Abadi M (2010) Distant metastases and malignant cellular neoplasms encountered in the oral and maxillofacial region: analysis of 92 patients treated at a single institution. Anticancer Res 30(5): 1843-1848.

40. Kaveri H, Punnya V, Tayaar A (2007) Metastatic thyroid carcinoma to the mandible. J Oral Maxillofac Pathol 11(1): 32-34.

41. Antunes AA, Antunes AP (2018) Gnathic bone metastasis: a retrospective study of 10 cases. Braz J Otorhinolaryngol 74(4): 561-565.

42. Harel R, Angelov L (2010) Spine metastases: Current treatments and future directions. Eur J Cancer 46(15): 2696-2707.

43. Fanchiang JK, Lin JD, Huang MJ, Shih HN (1998) Papillary and follicular thyroid carcinomas with bone metastases: a series of 39 cases during a period of 18 years. Chang yi xue za zhi 21(4): 377-382.

44. Bernier M-O, Leenhardt L, Hoang C, Aurengo A, Mary JY, et al. (2001) Survival and Therapeutic Modalities in Patients with Bone Metastases of Differentiated Thyroid Carcinomas. J Clin Endocrinol Metab. 86(4): 1568-1573. 


\section{Otolaryngology Open Access Journal}

45. Pittas AG, Adler M, Fazzari M, Tickoo S, Rosai J, et al. (2000) Bone Metastases from Thyroid Carcinoma: Clinical Characteristics and Prognostic Variables in One Hundred Forty-Six Patients. Thyroid 10(3):261268.

46. Schmidt GP, Schoenberg SO, Schmid R, Stahl R, Tiling $R$, et al. (2007) Screening for bone metastases: wholebody MRI using a 32-channel system versus dualmodality PET-CT. Eur Radiol 17(4): 939-949.

47. Ito S, Kato K, Ikeda M, Iwano S, Makino N, et al. (2007) Comparison of 18F-FDG PET and bone scintigraphy in detection of bone metastases of thyroid cancer. J Nucl Med 48(6): 889-895.

48. Chin BB, Patel P, Cohade C, Ewertz M, Wahl R, Ladenson P (2004) Recombinant Human Thyrotropin Stimulation of Fluoro- $d$-Glucose Positron Emission Tomography Uptake in Well-Differentiated Thyroid Carcinoma. J Clin Endocrinol Metab 89(1): 91-95.

49. Iwata M, Kasagi K, Misaki T, Matsumoto K, Iida Y, et al. (2004) Comparison of whole-body 18 F-FDG PET, 99m Tc-MIBI SPET, and post-therapeutic $131 \mathrm{I}-\mathrm{Na}$ scintigraphy in the detection of metastatic thyroid cancer. Eur J Nucl Med Mol Imaging 31(4): 491-498.

50. Robbins RJ, Wan Q, Grewal RK (2006) Real-Time Prognosis for Metastatic Thyroid Carcinoma Based on 2-[18 F] Fluoro-2-Deoxy- d -Glucose-Positron Emission Tomography Scanning. J Clin Endocrinol Metab 91(2): 498-505.

51. Freudenberg LS, Antoch G, Jentzen W, Pink R, Knust J, et al. (2004) Value of 124I-PET/CT in staging of patients with differentiated thyroid cancer. Eur Radiol 14(11): 2092-2098.

52. Rougraff BT (2003) Evaluation of the Patient with Carcinoma of Unknown Origin Metastatic to Bone. Clin Orthop Relat Res 415(415Suppl): S105-S109.

53. Cazzato RL, Bonichon F, Buy X, Godbert Y, de Figuereido B, et al. (2015) Over ten years of singleinstitution experience in percutaneous image-guided treatment of bone metastases from differentiated thyroid cancer. Eur J Surg Oncol 41(9): 1247-1255.

54. Selvakumar VPP, Goel A, Kumar K (2016) Cervical Cord Compression as Initial Presentation of Papillary Thyroid Carcinoma: a Case Report. Indian J Surg Oncol 7(3): 349-352.
55. McNeeley MF, Sabath A, Linnau KF (2012) Follicular thyroid carcinoma presenting as acute cord compression due to thoracic vertebral metastasis. Radiol case reports 7(3): 687.

56. Haugen BR, Alexander EK, Bible KC, Doherty GM, Mandel SJ, et al. (2016) 2015 American Thyroid Association Management Guidelines for Adult Patients with Thyroid Nodules and Differentiated Thyroid Cancer: The American Thyroid Association Guidelines Task Force on Thyroid Nodules and Differentiated Thyroid Cancer. Thyroid 26(1): 1-133.

57. Dong P, Chen N, Li L, Huang R (2017) An upper cervical cord compression secondary to occult follicular thyroid carcinoma metastases successfully treated with multiple radioiodine therapies: A clinical case report. 96(41): 8215 .

58. Greenblatt DY, Chen H (2007) Palliation of advanced thyroid malignancies. Surg Oncol 16(4): 237-247.

59. Rosen HN, Moses AC, Garber J, Ross DS, Lee SL, et al. (1998) Randomized Trial of Pamidronate in Patients with Thyroid Cancer: Bone Density Is Not Reduced by Suppressive Doses of Thyroxine, But Is Increased by Cyclic Intravenous Pamidronate. J Clin Endocrinol Metab 83(7): 2324-2330.

60. Vitale G, Fonderico F, Martignetti A, Caraglia M, Ciccarelli A, et al. (2001) Pamidronate improves the quality of life and induces clinical remission of bone metastases in patients with thyroid cancer. Br J Cancer 84(12): 1586-1590.

61. Polascik TJ (2009) Bisphosphonates in oncology: evidence for the prevention of skeletal events in patients with bone metastases. Drug Des Devel Ther 3: $27-40$.

62. Besic N, Schwarzbartl-Pevec A, Vidergar-Kralj B, Crnic T, Gazic B, et al. (2016) Treatment and outcome of 32 patients with distant metastases of Hürthle cell thyroid carcinoma: a single-institution experience. BMC Cancer 16: 162.

63. Lopez-Penabad L, Chiu AC, Hoff AO, Schultz P, Gaztambide S, et al. (2003) Prognostic factors in patients with Hürthle cell neoplasms of the thyroid. Cancer 97(5): 1186-1194.

64. McHenry CR, Phitayakorn R (2011) Follicular adenoma and carcinoma of the thyroid gland. Oncologist 16(5): 585-593. 


\section{Otolaryngology Open Access Journal}

65. Tsang RW, Brierley JD, Simpson WJ, Panzarella T, Gospodarowicz MK, et al. (1998) The effects of surgery, radioiodine, and external radiation therapy on the clinical outcome of patients with differentiated thyroid carcinoma. Cancer 82(2): 375-388.

66. Foote RL, Brown PD, Garces YI, McIver B, Kasperbauer JL (2003) Is there a role for radiation therapy in the management of Hürthle cell carcinoma? Int J Radiat Oncol Biol Phys 56(4):10671072.

67. Brierley JD, Tsang RW (2008) External beam radiation therapy for thyroid cancer. Endocrinol Metab Clin North Am 37(2): 497-509.

68. Schwartz DL, Lobo MJ, Ang KK, et al. (2009) Postoperative External Beam Radiotherapy for Differentiated Thyroid Cancer: Outcomes and Morbidity with Conformal Treatment. Int J Radiat Oncol 74(4): 1083-1091.

69. Sandri A, Carbognin G, Regis D, Gaspari D, Calciolari C, et al. (2010) Combined radiofrequency and kyphoplasty in painful osteolytic metastases to vertebral bodies. Radiol Med 115(2): 261-271.

70. Toyota N, Naito A, Kakizawa H, Hieda M, Hirai N, et al. (2005) Radiofrequency Ablation Therapy Combined with Cementoplasty for Painful Bone Metastases: Initial Experience. Cardiovasc Intervent Radiol. 28(5): 578-583.

71. Robinson D, Yassin M, Nevo Z (2004) Cryotherapy of Musculoskeletal Tumors-From Basic Science to Clinical Results. Technol Cancer Res Treat 3(4): 371375.

72. Eustatia-Rutten CFA, Romijn JA, Guijt MJ, Vielvoye GJ, van den Berg R, et al. (2003) Outcome of Palliative Embolization of Bone Metastases in Differentiated Thyroid Carcinoma. J Clin Endocrinol Metab 88(7): 3184-3189.

73. Saad F, Lipton A (2010) SRC kinase inhibition: Targeting bone metastases and tumor growth in prostate and breast cancer. Cancer Treat Rev 36(2): 177-184.
74. Koreckij T, Nguyen H, Brown LG, Yu EY, Vessella RL, et al. (2009) Dasatinib inhibits the growth of prostate cancer in bone and provides additional protection from osteolysis. Br J Cancer 101(2): 263-268.

75. Gucalp A, Sparano JA, Caravelli J, Santamauro J, Patil S, et al. (2011) Phase II Trial of Saracatinib (AZD0530), an Oral SRC-inhibitor for the Treatment of Patients with Hormone Receptor-negative Metastatic Breast Cancer. Clin Breast Cancer 11(5): 306-311.

76. Hannon RA, Clack G, Rimmer M, Swaisland A, Lockton JA, et al. (2010) Effects of the Src kinase inhibitor saracatinib (AZD0530) on bone turnover in healthy men: A randomized, double-blind, placebo-controlled, multiple-ascending-dose phase I trial. J Bone Miner Res 25(3): 463-471.

77. Buijs JT, Stayrook KR, Guise TA (2011) TGF- $\beta$ in the Bone Microenvironment: Role in Breast Cancer Metastases. Cancer Microenviron 4(3): 261-281.

78. Connolly EC, Freimuth J, Akhurst RJ (2012) Complexities of TGF- $\beta$ targeted cancer therapy. Int J Biol Sci 8(7): 964-978.

79. Drooger JC, van der Padt A, Sleijfer S, Jager A (2013) Denosumab in breast cancer treatment. Eur J Pharmacol 717(1-3): 12-19.

80. Grávalos C, Rodríguez C, Sabino A, Segui MA, Virizuela JA, et al. (2016) SEOM Clinical Guideline for bone metastases from solid tumours (2016). Clin Transl Oncol 18(12): 1243-1253.

81. Ell B, Mercatali L, Ibrahim T, Campbell N, Schwarzenbach H, et al. (2013) Tumor-Induced Osteoclast miRNA Changes as Regulators and Biomarkers of Osteolytic Bone Metastasis. Cancer Cell 24(4): 542-556.

82. Krzeszinski JY, Wei W, Huynh H, Jin Z, Wang X, et al. (2014) miR-34a blocks osteoporosis and bone metastasis by inhibiting osteoclastogenesis and Tgif2. Nature 512(7515): 431-435. 